\title{
Disposable screen-printed sensors for determination of duloxetine hydrochloride
}

Nawal A Alarfaj ${ }^{1}$, Reda A Ammar ${ }^{1,2}$ and Maha F El-Tohamy ${ }^{1 *}$

\begin{abstract}
A screen-printed disposable electrode system for the determination of duloxetine hydrochloride (DL) was developed using screen-printing technology. Homemade printing has been characterized and optimized on the basis of effects of the modifier and plasticizers. The fabricated bi-electrode potentiometric strip containing both working and reference electrodes was used as duloxetine hydrochloride sensor. The proposed sensors worked satisfactorily in the concentration range from $1.0 \times 10^{-6}-1.0 \times 10^{-2} \mathrm{~mol} \mathrm{~L}^{-1}$ with detection limit reaching $5.0 \times 10^{-7} \mathrm{~mol} \mathrm{~L}^{-1}$ and adequate shelf life of 6 months. The method is accurate, precise and economical. The proposed method has been applied successfully for the analysis of the drug in pure and in its dosage forms. In this method, there is no interference from any common pharmaceutical additives and diluents. Results of the analysis were validated statistically by recovery studies.
\end{abstract}

Keywords: Disposable screen printed carbon electrode, Potentiometry, Duloxetine hydrochloride, Pharmaceutical preparations

\section{Introduction}

Duloxetine hydrochloride (DL), chemically known as $(+)$ (S) - N-methyl - $\gamma$ - (1- naphthyloxy) -2-thiophenepropylamine hydrochloride [1], is an antidepressant agent. It is indicated for the treatment of major depressive disorder (MDD) and general anxiety disorder. It is a selective serotonin and nor-epinephrine reuptake inhibitor (SSNRI) for oral administration. It is also used to treat fibromyalgia (a chronic pain disorder), or chronic muscle or joint pain (such as low back pain and osteoarthritis pain). It may also used to treat pain caused by nerve damage in people with diabetes [2]. DL is considered among the most important antidepressant drugs therefore, the development of reliable rapid and accurate procedures for this active ingredient quantification is welcomed [3]. A survey of literature showed that several analytical methods have been reported for determination of DL in its pure form, pharmaceutical preparations and biological fluids, where DL is not determined officially in any pharmacopoeia. These methods include high-performance liquid chromatography $[4,5]$, liquid chromatography coupled with mass spectrometry

\footnotetext{
* Correspondence: star2000star@gmail.com

'Department of Chemistry, College of Science, King Saud University, P.O. Box 22452, Riyadh 11495, Saudi Arabia

Full list of author information is available at the end of the article
}

[6-8], high performance thin layer chromatography [9], Spectrofluorimetry [10], spectrophotometry [11] and capillary zone electrophoresis [12]. Although, those methods are very sensitive, they are not adapted for in situ and real time detection of DL as they are time consuming, involve expensive apparatus and require skilled technicians.

Electrochemical techniques are of choice since they possess the advantages of simplicity, accuracy, and low cost without separation or pretreatment procedures [13]. The conventional Polyvinylchloride (PVC) membrane ionselective electrodes have found a wide range of applications in pharmaceutical analysis; however they still have certain inherent limitations. Drawbacks in the use of PVC electrodes were arisen from the time consuming and inconsistent manual fabrication typically employed as well as short lifetime of these electrodes [14].

To overcome the aforementioned difficulties in PVC membrane electrodes, new kinds of all solid- state ones (without internal reference solution) allowing electrode miniaturization capability were introduced. Coated wire electrodes (CWEs) and coated graphite electrodes are examples of these sensors design; however the potential drift and the poor adhesion of the membrane to the metal substrate are main drawbacks of these electrodes [15]. Carbon paste electrodes (CPEs) had been employed as
(C) ChemistryCentral

(ㄷ) 2010 Alarfaj et $\mathrm{al}_{\text {, }}$ licensee BioMed Central Ltd. This is an open access article distributed under the terms of the Creative Commons Attribution License (http://creativecommons.org/licenses/by/2.0), which permits unrestricted use, distribution, and reproduction in any medium, provided the original work is properly cited. 
useful materials for the fabrication of simple sensors since 1970s [16]. In comparison to PVC electrodes the CPEs possessed advantages of much lower Ohmic resistance, very fast and stable response with easy renewal of the electrode surface as well as long functional lifetime. As CPEs continued to play a major role in the development of analytical procedures or testing new analytical methodology, screen-printed electrodes (SPEs) could be considered a solution for the lack of commercial availability of CPEs. Screen printing seems to be one of the most promising technologies providing high versatility, reproducibility, and large-scale production for commercialization [17].

The present work aimed to introduce disposable screenprinted carbon electrodes (SPCEs) as potentiometric sensors using homemade carbon ink. SPCEs were fabricated in plain and modified forms, and then subjected to a series of tests to select the sensor possessing the most favorable analytical characteristics for their application as potentiometric sensor for DL determination in bulk drug and in its pharmaceutical formulations.

\section{Experimental}

\subsection{Reagents}

All reagents were of analytical grade and distilled water was used throughout the experiments. Di-butyl phthalate (DBP), di-octyl phthalate (DOP), di-octyl sebacate (DOS) and di-butyl sebacate (DBS), (Sigma-Aldrich) were used as electrode plasticizers. Poly (vinyl chloride) (PVC), with relative high molecular weight, phosphomolybdic acid (PMA), phosphotungstic acid (PTA), ammonium reineckate salt (ARS), acetone, cyclohexanone and tetrahydrofuran (THF) were from (Sigma-Aldrich, Germany) and graphite powder, synthetic 1-2 $\mu \mathrm{m}$, (Dorset, UK) were applied in electrode fabrication. Duloxetine hydrochloride was kindly supplied from Jean Radne Sales (Indian). Cymbalta $^{\circledR} 60 \mathrm{mg} /$ capsule was purchased from local drug stores.

\subsection{Apparatus}

Potential measurements were carried out using HANNA pH meter 211 with a combined pH glass electrode. Scanning electron microscope (JEOL JSM-6060 LV-Japan) was used for surface structure studies.

\subsection{Authentic samples}

Stock drug solution $0.1 \mathrm{~mol} \mathrm{~L}^{-1}$ was prepared by dissolving $1.7 \mathrm{~g}$ of the drug in distilled water, filtered and completed to $50 \mathrm{~mL}$ with distilled water.

\subsection{Pharmaceutical preparation}

The content of ten capsules of Cymbalta ${ }^{\circledR} 60 \mathrm{mg} / \mathrm{cap}$ sule was weighed, ground, and an accurate weight of the powder assigned to contain $100 \mathrm{mg}$ DL was dissolved in distilled water, filtered and completed to $50 \mathrm{~mL}$ with distilled water.

\subsection{Composition of screen printing carbon electrodes}

SPCEs are heterogeneous carbon electrodes having a composite structure since the printing ink matrix colligates different phases (carbon powder, plasticizer and polymeric binder which is PVC dissolved in a proper organic solvent). After printing and curing, carbon tracks were deposited on the substrate with a final composition of $34.6 \%$ plasticizer, $57.7 \%$ carbon and $7.7 \%$ polymeric binder. This composition combines those of both carbon pastes (28.6\% plasticizer and $71.4 \%$ carbon) and PVC membranes (50\% plasticizer, and 50\% PVC). Scanning electron microscopy (SEM) indicated that addition of the plasticizer into the printing carbon ink produced a semiliquid phase with smooth electrode surface (Figure 1). Such unique composition makes the SPCEs to combine the electroanalytical behavior of both PVC and CPE.

\subsection{Optimization of electrode performance}

\subsubsection{Plain or soaked electrodes}

Homemade carbon ink was prepared by mixing of $0.8 \mathrm{~g}$ carbon powder, $0.5 \mathrm{~g}$ plasticizer and $1.3 \mathrm{~g} 8 \% \mathrm{PVC}$ binder dissolved in a proper organic solvent $5 \mathrm{~mL}$ (THF). It is expected that during soaking of such electrode in the aqueous DL-ion pair(s) suspension, the electrode plasticizer extracts these ion-pair(s) and the electrode bulk becomes gradually saturated with such ion-pair(s), and hence there is no need to incorporate the ion exchanger into the electrode during its preparation. The plain SPCEs were soaked in different DL-ion pair(s) suspensions and used in potentiometric determination of DL hydrochloride [18].

\subsubsection{Modified electrode with duloxetine- ion pairs}

DL forms water-insoluble ion pair complexes with $20 \mathrm{mg}$ for each ammonium reineckate salt (ARS), phosphotungstic acid (PTA) and phosphomolybdic acid (PMA) which can be used as electoactive materials for DL sensors.

\subsubsection{Modified electrode with the ion pairing agents (in situ mode)}

In the modified electrode with ion pairing agents a suitable ion pairing agent PMA, 10 to $50 \mathrm{mg}$ was used in the printing ink followed by soaking of printed electrodes in DL solution led to the formation of DL-ion pairs at electrode surface which were subsequently extracted by the electrode mediator (plasticizer) into the electrode bulk solution.

\subsubsection{Effect of plasticizer type}

In this study the effect of plasticizer type on the performance of screen printing carbon electrodes has been studied. Four plasticizers, dioctylphthalate (DOP), dibutylphthalate (DBP), dioctylsebacate (DOS) and 
(a)
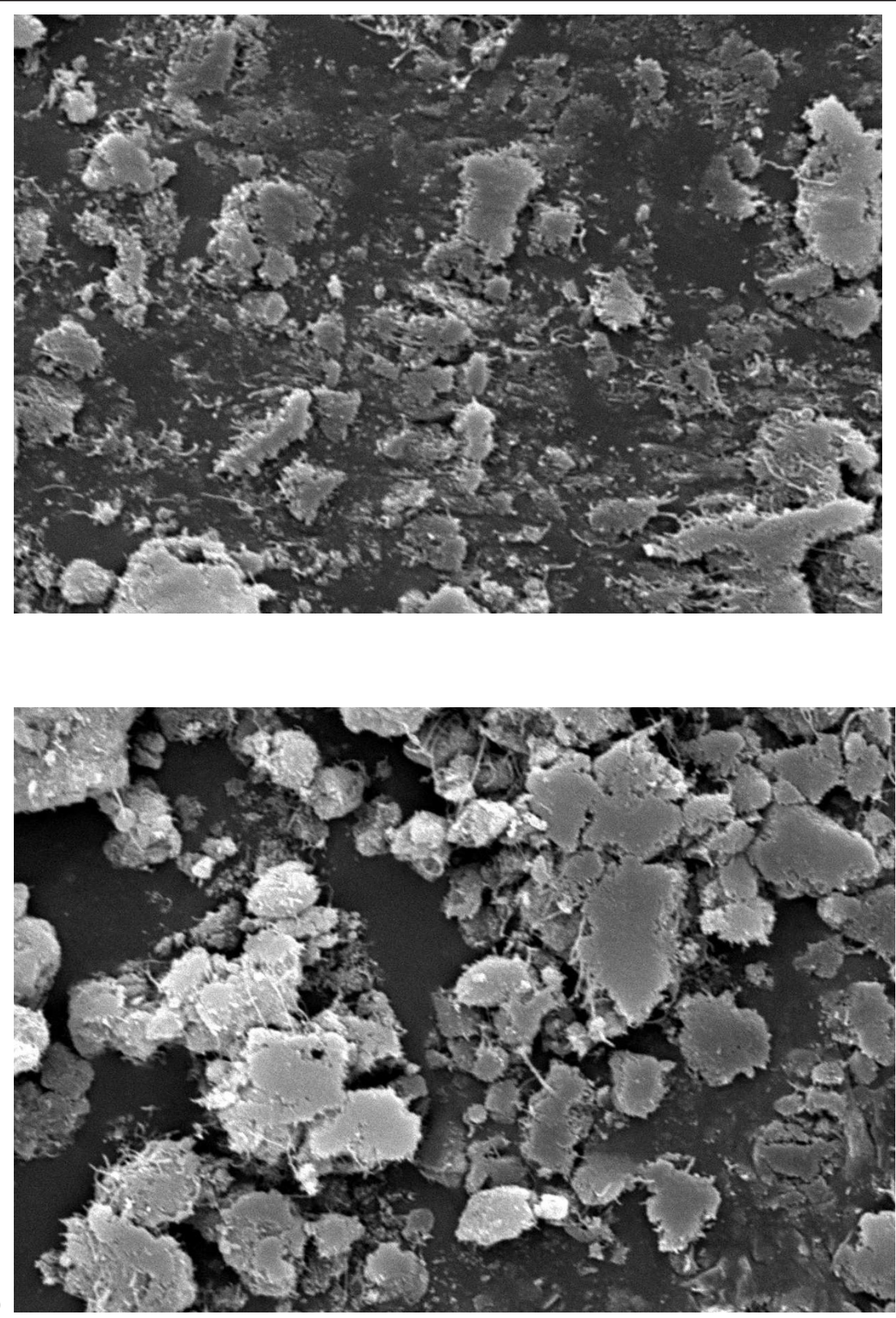

Figure 1 Scanning electron micrographs of electrode surface. a) Carbon ink containing DOP, b) Carbon ink without DOP.

diobutylsebacte (DBS) were used to examine the optimization of electrode performance. The content ratio were: for plasticizer 34.6, 45.0, 40.5 and $36.7 \mathrm{w} \%$, for Carbon powder $57.7,45.0,54.8$ and $55.5 \mathrm{w} \%$ and for PVC 7.7, 10.0, 8.5 and $4.5 \mathrm{w} \%$.

\subsubsection{Sensors construction}

The potentiometric strips were fabricated in arrays of six couples consisting of the working and reference electrodes (each $5 \times 35 \mathrm{~mm}$ ) following the procedures described elsewhere [17]. $\mathrm{Ag} / \mathrm{AgCl}$ pseudo-reference 
electrode was first printed using homemade ink (prepared by mixing $0.9 \mathrm{~g} \mathrm{Ag} / \mathrm{AgCl}$ mixture (65:35\%) with $0.8 \mathrm{~g}$ of $8 \%$ PVC solution in acetone-cyclohexanone mixture) and cured at $60^{\circ} \mathrm{C}$ for $30 \mathrm{~min}$. The plain carbon electrode was printed using carbon ink (prepared by mixing $0.5 \mathrm{~g}$ DOP, $1.3 \mathrm{~g}$ of $8 \% \mathrm{PVC}$ solution and 0.8 g carbon powder), cured at $50^{\circ} \mathrm{C}$ for $30 \mathrm{~min}$ and soaked in freshly prepared DL-ion pair suspensions for $24 \mathrm{~h}$. The modified electrodes were fabricated in the same manner with incorporation of either $20 \mathrm{mg}$ of phosphomolybdic acid ion pair or $50 \mathrm{mg}$ ammonium reineckate ion pair as senescing materials and used directly in the potentiometric measurements after $10 \mathrm{~min}$ preconditioning in $1.0 \times 10^{-3} \mathrm{~mol} \mathrm{~L}^{-1} \mathrm{DL}$ solution.

\subsubsection{Potentiometric measurements}

The fabricated sensors were calibrated by immersing the bi-electrode strip in $5 \mathrm{~mL}$ aliquots of $1.0 \times 10^{-6}-1.0 \times$ $10^{-1} \mathrm{~mol} \mathrm{~L}^{-1} \mathrm{DL}$ solutions and the potential readings were plotted against drug concentration $(-\log [D L])$.

\subsubsection{Analytical applications}

Using standard addition method, an electrode was immersed into a sample of $5 \mathrm{~mL}$ with unknown concentration (ca. $1.0 \times 10^{-4} \mathrm{~mol} \mathrm{~L}^{-1}$ and the equilibrium potential of $E_{1}$ was recorded. Then $0.1 \mathrm{~mL}$ of $1.0 \times 10^{-1}$ mol L ${ }^{-1}$ standard solution of DL was added into the testing solution and the equilibrium potential of $E_{2}$ was obtained. From the change of $\Delta\left(E_{2}-E_{1}\right)$ one can determine the concentration of the testing sample [19].

In the potentiometric titration methods, aliquots of the sample solutions containing $1.0 \times 10^{-6}-1.0 \times 10^{-2}$ mol L ${ }^{-1}$ DL were titrated with standard phosphomolybdic acid solution and the electrode potential values were plotted against volume of the titrant added to estimate the end point.

\section{Results and discussion}

Both unmodified and modified electrodes (either with DL ion pairs or ion pairing agents) were prepared and tested for the effect of nature and content of modifier, type of plasticizer, $\mathrm{pH}$, response time, interferents, and applications.

\subsection{Response characteristics of DL-SPCEs sensors}

It is expected that during soaking of the plain electrode in the aqueous DL-ion pair(s) suspension, the electrode plasticizer extracts these ion-pair(s) and the electrode bulk becomes gradually saturated with such ion-pair(s), and hence there is no need to incorporate the ion exchanger into the electrode during its preparation. The plain SPCEs were soaked in different DL-ion pair(s) suspensions and used in potentiometric determination of DL hydrochloride. Results obtained showed that the electrodes soaked in DL-phosphomolybdate gave the best performance indicated by the highest slope $(57 \pm 0.4 \mathrm{mV}$ decade $^{-1}$ ) which may be attributed to the difference in solubility products of these ion pairs and their extraction into the electrode bulk solution [20], (Table 1).

DL forms water-insoluble ion pair complexes with ammonium reineckate salt (ARS), phosphotungstic acid (PTA) and phosphomolybdic acid (PMA) which can be used as electoactive materials for DL sensors. SPCEs incorporated with different DL ion-pairs gave Nernstain responses with different slopes and sensitivities depending on the nature of the ion pair used. Incorporation of DL-PMA showed the best performance (slope $55 \pm 2 \mathrm{mV}$ decade $^{-1}$ ) compared to the other DL-ion pairs modified electrodes. The content of DL-PMA in the printing ink was varied from 5 to $50 \mathrm{mg}$; incorporation of $20 \mathrm{mg}$ was found to be the best $\left(58 \pm 0.8 \mathrm{mV}\right.$ decade $\left.^{-1}\right)$ as further addition of this ion pair resulted in decreasing of the electrode slope as it reaches $47 \mathrm{mV}$ decade $^{-1}$.

Incorporation of a suitable ion pairing agent in the printing ink followed by soaking of printed electrodes in DL solution led to the formation of DL-ion pairs at electrode surface which were subsequently extracted by the electrode mediator (plasticizer) into the electrode bulk solution. From different incorporated ion-pairing agents, phosphomolybdic acid showed superior sensitivity indicated by the highest slope value $\left(54 \pm 2 \mathrm{mV}\right.$ decade $\left.^{-1}\right)$ compared to the other ion pairing agents. Carbon inks containing 10 to $50 \mathrm{mg}$ phosphomolybdic acid were prepared and used in printing of electrodes and calibration results revealed that SPCEs containing $50 \mathrm{mg}$ of phosphomolybdic acid showed the highest slope $(55 \pm 2 \mathrm{mV}$ decade $\left.^{-1}\right)$.

\subsection{Plasticizer effect}

The influence of the plasticizer on the electrode performance has been studied by comparing the DOP plasticized electrode with those plasticized with DBP, DOS and DBS Figure 2. The obtained calibration graphs of plain SPCEs clarified that, using DOP as plasticizer offers better sensitivity indicated by the highest slope (slope values were 58 $\pm 0.7,53 \pm 0.9,54 \pm 1$ and $55 \pm 0.8 \mathrm{mV}$ decade $^{-1}$ for DOP, DBP, DOS and DBS, respectively) which may be related to the dielectric constant of plasticizers and their abilities to extract DL-PMA into the electrode matrices $(\varepsilon=17.6,3.8$, 4.5 and 5.2 for tested plasticizers, respectively).

\subsection{Sensors performance}

The potentiometric response characteristics of DL-SPCEs were evaluated according to IUPAC recommendations [21]. Sensors displayed (Table 2) linear response from $1.0 \times 10^{-6}$ to $1.0 \times 10^{-2} \mathrm{~mol} \mathrm{~L}^{-1} \mathrm{DL}$ with Nernstian cationic slopes depending on the mode of preparation. Both SPCEs modified with the DL-PMA and plain electrodes showed better performance relative to those incorporated with the ion pairing agent indicated by higher slopes ( 58 
Table 1 Optimization of composition (w/w \%) of SPCEs sensors

\begin{tabular}{|c|c|c|c|c|c|c|c|c|c|}
\hline Types & No & $\begin{array}{l}\text { PVC } \\
\text { w\% }\end{array}$ & $\begin{array}{l}\text { DOP } \\
\text { w\% }\end{array}$ & $\begin{array}{l}\text { Carbon } \\
\text { w\% }\end{array}$ & $\begin{array}{l}\text { DL-PMA } \\
\text { (mg) }\end{array}$ & $\begin{array}{l}\text { PMA } \\
(\mathrm{mg})\end{array}$ & Slope & \%RSD* & $\begin{array}{l}\text { Linear Conc. } \\
\text { Range }\left(\mathrm{Mol} \mathrm{L}^{-1}\right)\end{array}$ \\
\hline \multirow[t]{3}{*}{$\begin{array}{c}\text { Plain } \\
\text { (Soaking electrode) }\end{array}$} & (a) & 7.7 & 34.6 & 57.7 & - & - & 57.0 & 0.4 & $1.0 \times 10^{-6}-1.0 \times 10^{-2}$ \\
\hline & (b) & 10.0 & 45.0 & 45.0 & - & - & 56.0 & 1.2 & $1.0 \times 10^{-5}-1.0 \times 10^{-2}$ \\
\hline & (c) & 8.5 & 36.7 & 54.8 & - & - & 54.0 & 0.9 & $1.0 \times 10^{-5}-1.0 \times 10^{-2}$ \\
\hline \multirow[t]{3}{*}{ Modified } & (a) & 7.7 & 34.6 & 57.7 & 20 & -— & 58.0 & 0.8 & $1.0 \times 10^{-6}-1.0 \times 10^{-2}$ \\
\hline & (b) & 10.0 & 45.0 & 45.0 & 20 & - - & 57.5 & 0.2 & $5.0 \times 10^{-5}-1.0 \times 10^{-2}$ \\
\hline & (c) & 8.5 & 36.7 & 54.8 & 20 & - - & 55.0 & 0.6 & $1.0 \times 10^{-6}-1.0 \times 10^{-2}$ \\
\hline \multirow[t]{3}{*}{ In situ } & (a) & 7.7 & 34.6 & 57.7 & - & 50 & 55.0 & 0.4 & $1.0 \times 10^{-6}-1.0 \times 10^{-2}$ \\
\hline & (b) & 10.0 & 45.0 & 45.0 & - & 50 & 52.0 & 0.7 & $1.0 \times 10^{-5}-1.0 \times 10^{-2}$ \\
\hline & (c) & 8.5 & 36.7 & 54.8 & - & 50 & 54.5 & 0.8 & $1.0 \times 10^{-6}-1.0 \times 10^{-3}$ \\
\hline
\end{tabular}

* Average of five determinations

\pm 0.8 and $57 \pm 0.4 \mathrm{mV}$ decade $^{-1}$ ) with lower detection limit reaching $5.0 \times 10^{-7} \mathrm{~mol} \mathrm{~L}^{-1}$. Screen-printing technology offers production reproducibility, versatility, and large-scale production for commercialization. Concerning the fabrication reproducibility, modification with DLPMA was the best as the average slope values for six electrodes within the same batch were $58 \pm 0.8 \mathrm{mV}$ decade $^{-1}$ with standard potential $37 \pm 2 \mathrm{mV}$. The corresponding values between three different batches were $59 \pm 1 \mathrm{mV}$ decade $^{-1}$ and $375 \pm 2.7 \mathrm{mV}$, respectively. The lifetimes of the different fabricated electrodes were tested by performing day-to-day calibration. SPCEs showed a useful lifetime of 4 weeks of daily measurement, during which the average slopes were reproducible (within $\pm 2 \mathrm{mV}$ decade $\left.^{-1}\right)$. Moreover, the SPCEs showed shelf life of more than 6 months when stored dry at $4{ }^{\circ} \mathrm{C}$ without significant change in the electrode performance. The dynamic response time of the electrode was tested by measuring the time required to achieve a steady state potential (within $\pm 1 \mathrm{mV}$ ) after sudden increase in the DL concentration from $1.0 \times 10^{-6}$ to $1.0 \times 10^{-2} \mathrm{~mol} \mathrm{~L}^{-1}$. The response time of both plain and DL-PMA modified SPCEs was fast (as about $2.8 \mathrm{~s}$ ); while electrodes modified with the ion pairing agents gave a stable potential reading after $5 \mathrm{~s}$. The influence of $\mathrm{pH}$ on the response of SPCEs was also checked by recording the potential readings of the cell in solutions containing $1.0 \times 10^{-4}$ to $1.0 \times 10^{-2}$ mol L ${ }^{-1} \mathrm{DL}$ at different $\mathrm{pH}$ values ( $\mathrm{pH}$ 2-9). The plots of $\mathrm{E}(\mathrm{mV})$ versus $\mathrm{pH}$ indicated that the electrodes responses were found to be $\mathrm{pH}$-independent in the range 3-8 (Figure 2). Selectivity coefficients of DL-SPCEs were determined using separate solution method [19] and matched solution method [22]. Additives and fillers commonly introduced in pharmaceutical formulations (such as glycine, caffeine, citrate, maltose, sucrose, and starch) as well as inorganic cations, $\mathrm{Na}^{+}, \mathrm{K}^{+}, \mathrm{Li}^{+}, \mathrm{Ca}^{2+}, \mathrm{Mg}^{2+}$, and $\mathrm{NH}_{4}{ }^{+}$did not show significant interference in the determination of DL (Table 3).

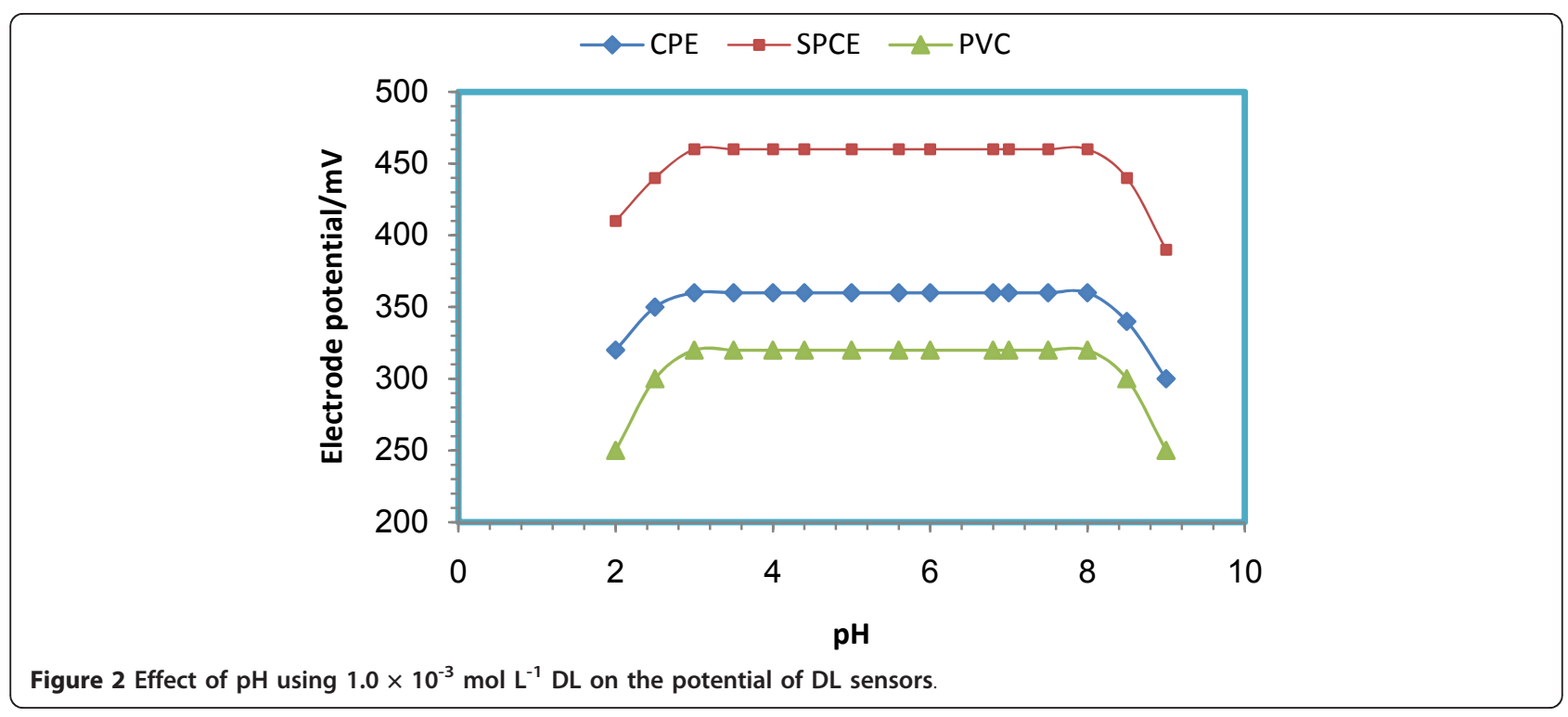


Table 2 Analytical performance of various DL-SPCEs

\begin{tabular}{cccc}
\hline Parameter & Modified & In situ & Plain (Soaked) \\
\hline Concentration range $\left(\mathrm{mol} \mathrm{L}^{-1}\right)$ & $1.0 \times 10^{-6}-1.0 \times 10^{-2}$ & $1.0 \times 10^{-6}-1.0 \times 10^{-2}$ & $1.0 \times 10^{-6}-1.0 \times 10^{-2}$ \\
Slope $\left(\mathrm{mV}\right.$ decade $\left.{ }^{-1}\right)$ & $58 \pm 1$ & $55 \pm 2$ & $57 \pm 0.4$ \\
Correlation coefficient, $r$ & 0.9999 & 0.9998 & 0.9999 \\
LOD $\left(\mathrm{mol} \mathrm{L}^{-1}\right)$ & $5.0 \times 10^{-7}$ & $5.0 \times 10^{-7}$ & $5.0 \times 10^{-7}$ \\
Response time $(\mathrm{s})$ & 2.8 & 5.0 & 2.8 \\
Operation lifetime (days) & 27 & 20 & 20 \\
Shelf lifetime (months) & 6 & 6 & 6 \\
Working pH range & $3-8$ & $3-8$ & $3-8$ \\
\hline
\end{tabular}

Results are average of five different determinations

\subsection{Potentiometric titration}

In addition to the application of SPCEs in direct potentiometric determination of DL hydrochloride, the developed sensors were also used as end-point indicator electrodes in the potentiometric titration of DL hydrochloride with phosphomolybdic acid. The effect of electrode plasticizer on the titration performance was also investigated. Generally, the printed electrodes plasticized with DOP gave the highest total potential change $(\triangle \mathrm{E}=$ $380 \mathrm{mV}$ ) compared with those plasticized with DBS, DOS and DBP $(\triangle \mathrm{E}=180,148$ and $90 \mathrm{mV}$ for the plasticizers in the same order). Moreover, plain SPCEs showed the best titration curve (Figure 3) comparable to those modified with either the DL-PMA or ion-pairing agent. Under the same conditions, SPCEs showed a better titration curve than that obtained with CPEs and similar to PVC electrode (Figure 4). The titration curves were symmetrical with very well-defined inflexion points of potential jumps indicating the high sensitivity of the

Table 3 Selectivity and tolerance values for the DL-PMA responsive sensors

\begin{tabular}{|c|c|c|}
\hline \multicolumn{3}{|c|}{$-\log \mathrm{K}_{\mathrm{Dl}, \mathrm{J}^{\mathrm{pot}}}^{\mathrm{z}}$} \\
\hline \multirow[t]{2}{*}{ Interferent } & \multicolumn{2}{|c|}{ DL-PMA } \\
\hline & SSM & MSM \\
\hline$\overline{\mathrm{Na}^{+}}$ & 2.64 & 2.85 \\
\hline $\mathrm{K}^{+}$ & 2.99 & 3.12 \\
\hline $\mathrm{Li}^{+}$ & 2.65 & 2.98 \\
\hline $\mathrm{NH}_{4}^{+}$ & 2.87 & 3.23 \\
\hline $\mathrm{Ca}^{2+}$ & 3.77 & - \\
\hline $\mathrm{Mg}^{2+}$ & 3.12 & 3.28 \\
\hline $\mathrm{Cd}^{2+}$ & 3.89 & - \\
\hline$A l^{3+}$ & 3.74 & - \\
\hline $\mathrm{Fe}^{3+}$ & 4.65 & - \\
\hline Glycine & - & 4.54 \\
\hline Caffeine & - & 5.34 \\
\hline Glucose & - & 4.98 \\
\hline Lactose & - & 5.26 \\
\hline Sucrose & - & 5.35 \\
\hline Starch & - & 4.02 \\
\hline
\end{tabular}

electrode. The titration process was highly reproducible with average recoveries $99.6 \pm 0.8$ and $99.6 \pm 0.6 \%$ for $1.0 \times 10^{-2}$ and $1.0 \times 10^{-3} \mathrm{~mol} \mathrm{~L}^{-1} \mathrm{DL}$, respectively. It was found that the same electrode was successfully applied for more than 20 titration processes over 20 days with non-significant drift in the total potential change $(\Delta \mathrm{E}=286 \pm 1 \mathrm{mV})$ and average recovery of $99.98 \pm 0.8 \%$.

\subsection{Analytical applications}

The proposed electrodes were successfully employed for assay of DL in its authentic samples as well as pharmaceutical formulations applying standard addition, and potentiometric titration methods. The results in Table 4 clearly indicate satisfactory agreement between the DL contents in different samples determined by the developed sensor and the reported UV-spectrophotometric method [23] which includes the determination of duloxetine hydrochloride in $0.1 \mathrm{~mol} \mathrm{~L}^{-1} \mathrm{HCl}$ at $288 \mathrm{~nm}$.

\section{Conclusion}

The present study shows that, the SPCEs can be characterized, optimized, and successfully applied for the

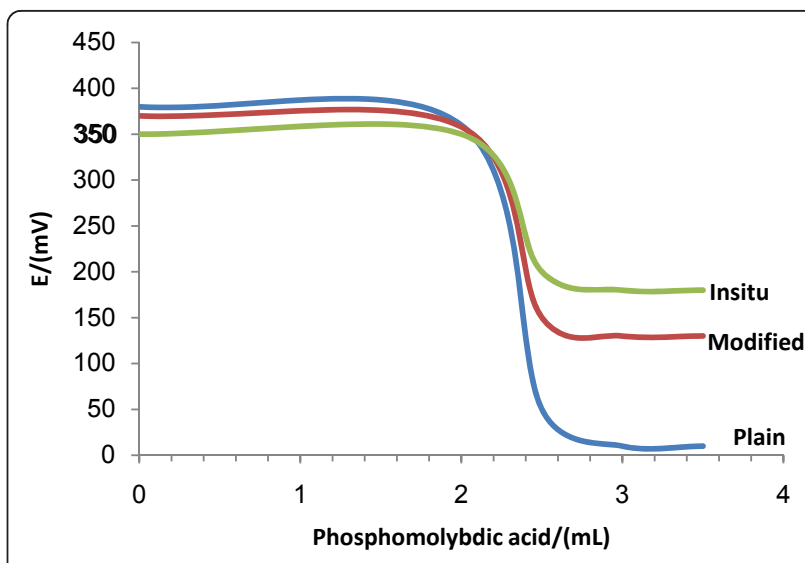

Figure 3 Potentiometric titration of DL with phosphomolybdic acid $5.0 \times 10^{-3} \mathrm{~mol} \mathrm{~L}^{-1}$ using SPCEs fabricated with different modes $\left(2.0 \mathrm{~mL}\right.$ of $\left.1.0 \times 10^{-2} \mathrm{~mol} \mathrm{~L}^{-1} \mathrm{DL}\right)$. 


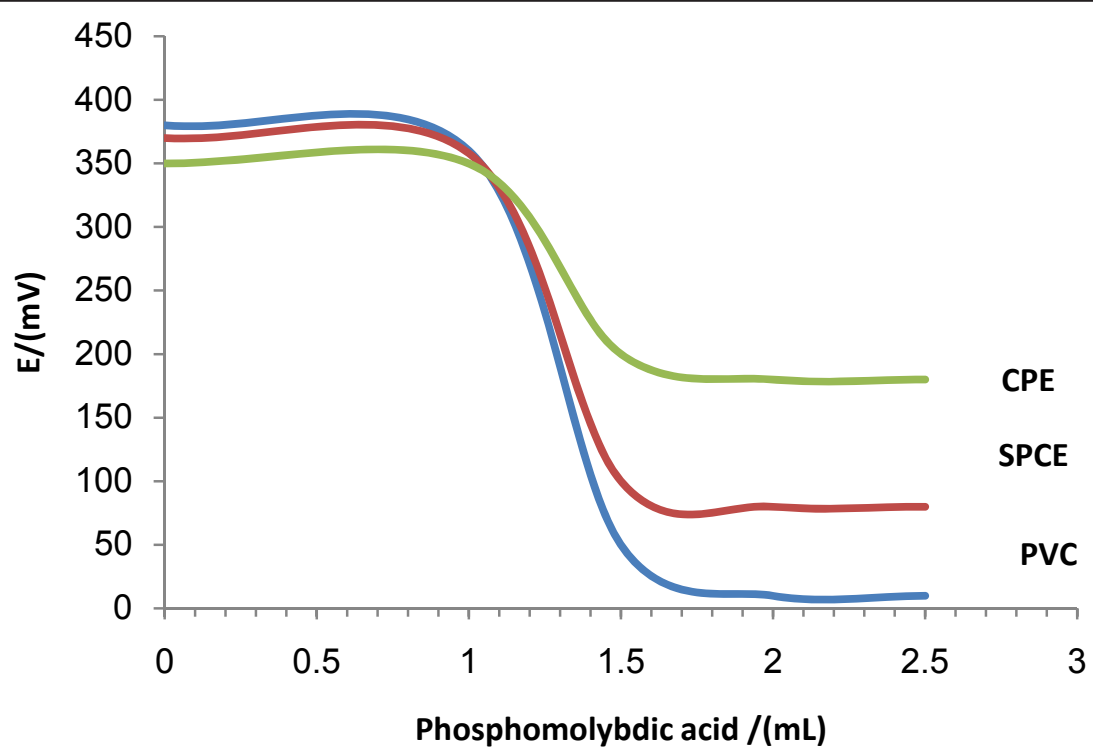

Figure 4 Potentiometric titration of DL with phosphomolybdic acid $5.0 \times 10^{-3} \mathrm{~mol} \mathrm{~L}^{-1}$ using SPCEs fabricated with different modes SPCE, PVC and CPEs (1.0 mL of $\left.1.0 \times 10^{-2} \mathrm{~mol} \mathrm{~L}^{-1} \mathrm{DL}\right)$.

Table 4 Potentiometric determination of DL in pharmaceutical preparation using SPCEs

\begin{tabular}{|c|c|c|c|c|c|c|c|}
\hline \multirow[t]{6}{*}{ Standard addition } & \multirow{2}{*}{$\begin{array}{l}\text {-log conc. taken } \\
\left(\mathrm{mol} \mathrm{L}^{-1}\right)\end{array}$} & \multicolumn{2}{|c|}{ Pure solution } & \multicolumn{2}{|c|}{ Cymbalta ${ }^{\circledR}$ tablets } & \multicolumn{2}{|c|}{ Reported method $^{23}$} \\
\hline & & $\begin{array}{c}\text { Recovery } \\
\%\end{array}$ & $\begin{array}{c}\text { RSD* } \\
\%\end{array}$ & $\begin{array}{c}\text { Recovery } \\
\%\end{array}$ & $\begin{array}{c}\text { RSD* } \\
\%\end{array}$ & $\begin{array}{c}\text { Recovery } \\
\%\end{array}$ & $\begin{array}{c}\mathrm{RSD}^{*} \\
\%\end{array}$ \\
\hline & 5.0 & 99.80 & 0.7 & 99.20 & 0.3 & & \\
\hline & 4.0 & 99.50 & 0.8 & 99.25 & 0.5 & 99.60 & 0.9 \\
\hline & 3.0 & 100.00 & 0.6 & 99.33 & 0.4 & 99.75 & 0.7 \\
\hline & 2.0 & 99.50 & 0.8 & 98.50 & 0.3 & 99.33 & 0.5 \\
\hline \multirow[t]{4}{*}{ Titration } & 5.0 & 99.60 & 0.2 & 99.40 & 0.6 & 99.50 & 0.2 \\
\hline & 4.0 & 99.25 & 0.5 & 99.00 & 0.9 & & \\
\hline & 3.0 & 99.33 & 0.1 & 99.67 & 0.3 & & \\
\hline & 2.0 & 99.00 & 0.6 & 99.00 & 0.8 & & \\
\hline
\end{tabular}

*Average of five determinations

potentiometric determination of DL using the procedures adapted in the application of the ordinary CPEs and PVC electrodes. SPCEs are produced more easily and rapidly, saving large amounts of reagents, especially sensing material. The developed disposable strips have several advantages including simplicity, versatility, reproducibility of the preparation, and low cost mass production. Moreover, the different DL sensors presented in this study showed fast dynamic response times and longer lifetimes. The electrochemical performance of the developed SPCEs was even better than the conventional ones and can be regarded as the base for further research on drug quality control via incorporation of different sensing materials.

\section{Acknowledgments}

The Authors extend their appreciation to the Deanship of Scientific Research at King Saud University for funding the work through the research group project No. RGP-VPP-062.

\section{Author details}

'Department of Chemistry, College of Science, King Saud University, P.O. Box 22452, Riyadh 11495, Saudi Arabia. ${ }^{2}$ Department of Chemistry, Collage of

Science, Al-Azhar University, Cairo, Egypt.

\section{Authors' contributions}

NAA participated the design of the study and performed the statistical analysis of the data, RAA provided the chemicals and pure materials, conceived of the study, participated in its design and coordination and MFE carried out the practical studies and write the manuscript. All The authors read and approved the manuscript.

\section{Competing interests}

The authors declare that they have no competing interests. 
Received: 19 October 2011 Accepted: 21 January 2012

Published: 21 January 2012

\section{References}

1. Sweetman SC: Martindale: The complete drug reference. 34 edition. London: Pharmaceutical Press; 2005, 292.

2. Brunton LL, Parker KS, Lazo JS: Goodman and Gillman's, the Pharmacological Basis of Therapeutics. 11 edition. London: McGraw Hill Publishing; 2005, 436.

3. Aboul-Enein HY, Stefan Rl: The opportunity to use ion-selective membrane electrodes for dissolution tests. Inst Sci \&Tech 1999, 27(2):89-93.

4. Raman NV, Harikrishna KA, Prasad AV, Reddy KR, Ramakrishna K. Determination of duloxetine hydrochloride in the presence of process and degradation impurities by a validated stability-indicating RP-LC method. J Pharm Biomed Anal 2010, 51(4):994-997.

5. Sinha VR, Anamika, Kumria R, Bhinge JR: Stress degradation studies on duloxetine hydrochloride and development of an RP-HPLC method for its determination in capsule formulation. J Chromatogr Sci 2009, 47(7):589-593.

6. Senthamil Selvan P, Gowda KV, Mandal U, Sam Solomon WD, Pal TK: Determination of duloxetine in human plasma by liquid chromatography with atmospheric pressure ionization-tandem mass spectrometry and its application to pharmacokinetic study. J Chromatogr B 2007, 858(1-2):269-275.

7. Ma N, Zhang BK, Li HD, Chen BM, Xu P, Wang F, Zhu RH, Feng S, Xiang DX, Zhu YG: Determination of duloxetine in human plasma via LC/MS and subsequent application to a pharmacokinetic study in healthy Chinese volunteers. Clin Chim Acta 2007, 380(1-2):100-105.

8. Satonin DK, McCulloch JD, Kuo F, Knadler MP: Development and validation of a liquid chromatography-tandem mass spectrometric method for the determination of the major metabolities of duloxetine in human plasma. J Chromatogr B 2007, 852(1-2):582-589.

9. Dhaneshwar SS, Deshpande P, Patil M, Vadnerkar G, Dhaneshwar SR: Development and validation of HPTLC method for estimation of duloxetine hydrochloride in bulk drug and in tablets dosage form. Indian J Pharm Sci 2008, 70(2):233-236.

10. Prabu SL, Shahnawaz S, Kumar CD, Shirwaikar A: Spectrofluorometric method for determination of duloxetine hydrochloride in bulk and pharmaceutical dosage forms. Indian J Pharm Sci 2008, 70(4):502-503.

11. Kamila MM, Mondal N, Ghosh LK: A validated UV spectrophotometric method for determination of duloxetine hydrochloride. Die Pharmazie 2007, 62(6):414-415.

12. Musenga A, Amore M, Mandrioli R, Kenndler E, de Martino L, Raggi MA: Determination of duloxetine in human plasma by capillary electrophoresis with laser-induced fluorescence detection. J Chromatogr B 2009, 877(11-12):1126-1132.

13. Cosofret W, Buck RP: Pharmaceutical Applications of membrane sensors CRC Press; Boca Raton, FL; 1992.

14. Abbas MN, Radwan AA: Novel lipoate-selective membrane sensor for the flow injection determination of a-lipoic acid in pharmaceutical preparations and urine. Talanta 2008, 74:1113-1121.

15. Singh AK, Singh P: Nano-level monitoring of $\mathrm{Yb}(\mathrm{III})$ by fabrication of coated graphite electrode based on newly synthesized hexaaza macrocyclic ligand. Anal Chim Acta 2009, 643(1-2):74-82.

16. Mesaric S, Dahmen EAMF: Ion selective carbon-paste electrodes for halides and silver (I) ions. Anal Chim Acta 1973, 64(3):431-438.

17. Khaled E, Hassan HN, Girgis A, Metelka R: Construction of novel simple phosphate screen-printed and carbon paste ion-selective electrodes. Talanta 2008, 77:737-743.

18. Elmorsy K, Hasan HNA, Gehad GM, Seleim AA: Ion selective electrode for the determination of trazodone in tablets. Talanta 2010, 81(1-2):510-515

19. Ma TS, Hassan SSM: In Organic analysis using ion selective electrode. Volume I and II. Academic Press, London; 1982.

20. Khaled E, Hassan HN, Mohamed GG, Seleim AE: Towards disposable sensors for drug quality control: Dextromethorphan screen-printed electrodes. Drug Test Anal 2010, 2:424-429.

21. Umezawa Y, Buhlmann P, Umezawa K, Tohda K, Amemiya S: Potentiometric selectivity coefficients of ion-selective electrodes, part I, inorganic cations (IUPAC Technical Report). Pure Appl Chem 2000, 72:1851-2082.
22. Buck RP, Lindner E: Recommendations for nomenclature of ion-selective electrodes. Pure Appl Chem 1994, 66:2527-2536.

23. Yunoos M, Sankar DG, Kumar BP, Hameed S, Hussain A: Simple UV spectrophotometric determination of duloxetine hydrochloride in bulk and in pharmaceutical formulations. E-journal of Chem 2010, 7(3):785-788.

doi:10.1186/1752-153X-6-6

Cite this article as: Alarfaj et al:: Disposable screen-printed sensors for determination of duloxetine hydrochloride. Chemistry Central Journal 2012 6:6.

Publish with ChemistryCentral and every
scientist can read your work free of charge
"Open access provides opportunities to our
colleagues in other parts of the globe, by allowing
anyone to view the content free of charge."
W. Jeffery Hurst, The Hershey Company.
- available free of charge to the entire scientific community
- cited in PubMed and archived on PubMed Central
- yours - you keep the copyright
Submit your manuscript here:
http://www.chemistrycentral.com/manuscript/

